\title{
Revista Brasileira de Enfermagem REBEn \\ O jogo de forças na reorganização da Escola Profissional de Enfermeiros e Enfermeiras
}

\author{
A major game in the re-organization of the Professional Nursing School \\ El juego de fuerzas en la reorganización de la Escuela Profesional \\ de Enfermeros y Enfermeras
}

\section{Wellington Mendonça de Amorin}

Doutor em História da Enfermagem; Professor Adjunto do Departamento de Enfermagem de Saúde Pública, da Escola de Enfermagem Alfredo Pinto, da UNIRIO, Rio de Janeiro, RJ. Pesquisador do Laboratório de Pesquisa de História de Enfermagem/ Laphe; Membro Fundador do Núcleo de

Pesquisa de História da Enfermagem Brasileira/Nuphebras/EEAN/UFRJ.

\section{Endereco para contato}

End. Praia do Flamengo 98 ap 1110, Flamengo- Rio de Janeiro - RJ. CEP 22210-902. amorimw@oi.com.br

\section{leda de Alencar Barreira}

Doutora em História da Enfermagem. Membro Fundador do Núcleo de Pesquisa de História da Enfermagem Brasileira Nuphebras, Rio de Janeiro, RJ. Exprofessora titular do Departamento de Enfermagem Fundamental /EEAN/UFRJ. Pesquisadora $1 A$ do CNPq. iedabarreira@openlink.com.br
Submissão: $18 / 07 / 2006$

Aprovação: $23 / 10 / 2006$

\section{RESUMO}

Estudo histórico social apoiado no pensamento de Pierre Bourdieu e baseado em análise documental. Descreve as ações dos sanitaristas e dos psiquiatras, a partir da reformulação do Ministério da Educação e Saúde Pública em Ministério da Educação e Saúde, no início do Estado Novo e analisa as estratégias de luta dos principais agentes, para fazer prevalecer suas propostas de reorganização da Escola Profissional de Enfermeiros e Enfermeiras. As estratégias de luta que psiquiatras, sanitaristas e enfermeiras diplomadas utilizaram para fazer valer seus projetos, caracterizaram uma árdua luta inserida em uma batalha mais ampla. A análise dos dez meses de tramitação do principal documento em causa evidencia o conflito entre estes agentes para impor uma nova ordem à Escola.

Descritores: História da enfermagem; Educação em enfermagem; Escolas de enfermagem.

\section{ABSTRACT}

This is a historical-social description study supported on the thought of Pierre Bourdieu based on documental analysis. It describes the sanitarists and psychiatrists' actions from the reformulation of Education and Public Health Ministry into Education and Health Ministry in the beginning of New State and analyse the fight's strategies of the main agents to take advantage on their proposals of Professional Nursing School's reorganization. The fight's strategies that psychiatrists, sanitarists and certificated nurses had used to stake their projects, characterized a difficult battle inserted in a hard major game. The analyse of the ten course's months of the main document shows the conflict between those agents to impose a new rule to the school.

Descriptors: History of nursing; Education, nursing; Nursing diploma courses.

\section{RESUMEN}

Estudio histórico social apoyado en el pensamiento de Pierre Bourdieu, basado en análisis documental. Describe las acciones de los sanitaristas y de los psiquiatras, a partir de la reformulación del Ministerio de la Educación y Salud Pública en Ministerio de la Educación y Salud, en el inicio del Estado Nuevo y analiza las estrategias de lucha de los principales agentes, para hacer prevalecer sus propuestas de reorganización de la Escuela Profesional de Enfermeros y Enfermeras. Las estrategias de lucha que psiquiatras, sanitaristas y enfermeras diplomadas utilizaron para hacer valer sus proyectos, caracterizaron una ardua lucha insertada en una batalla mayor. El análisis de los diez meses de tramitación del principal documento evidencia el conflicto entre estos agentes para imponer una nueva orden a la Escuela. Descriptores: Historia de la enfermería; Educación en enfermería; Escuelas de enfermería.

Amorin WM, Barreira IA. O jogo de forças na reorganização da Escola Profissional de Enfermeiros e Enfermeiras. Rev Bras Enferm 2007 jan-fev; 60(1):55-61.

\section{INTRODUÇÃO}

As condições históricas e políticas que permeariam a mudança da trajetória da Escola Profissional de Enfermeiros e Enfermeiras (EPEE), atual Escola de Enfermagem Alfredo Pinto, da UNIRIO, se consolidaram na primeira metade do Estado Novo (1937-1941). Coube ao Ministério da Educação e Saúde decidir, em última instância, como a Escola seria reorganizada. Esta decisão fundamentou-se na proposta resultante do jogo de forças entre psiquiatras, sanitaristas e enfermeiras diplomadas para a reorganização da Escola, no espaço do Departamento Nacional de Saúde.

O Diretor Geral do Departamento Nacional de Saúde (DNS), o sanitarista João de Barros Barreto, enquanto interlocutor dos grupos concorrentes no campo, ocupou posição privilegiada nesta luta. Muito embora tenha se confrontado com as especificidades de cada grupo, ele procurou, no contexto da reforma Capanema, defender os interesses dos sanitaristas do Departamento. 
Assim o objeto deste estudo são as relações de forças existentes entre os agentes médicos psiquiatras e sanitaristas e as enfermeiras diplomadas, no início do processo de reorganização da Escola Profissional de Enfermeiros e Enfermeiras, a partir da reformulação do Ministério da Educação e Saúde Pública (MESP) em Ministério da Educação e Saúde (MES) em 1937, sob o ideário do Estado Novo.

Para operacionalizar a pesquisa definimos como objetivos: descrever as ações dos sanitaristas e dos psiquiatras, a partir da reformulação do MESP em MES, no início do Estado Novo; e analisar as estratégias de luta dos principais agentes, para fazer prevalecer suas propostas de reorganização da EPEE.

\section{METODOLOGIA}

Pesquisa de natureza histórico-social, apoiada no pensamento de Pierre Bourdieu e baseada em análise documental. Nesta priorizamos a busca dos nexos entre as idéias contidas nos discursos, relacionando texto e contexto.

Para Bourdieu, o Estado tem a capacidade de regular o funcionamento dos diferentes campos, por meio de intervenções financeiras e legislativas ${ }^{(1)}$. Destacamos aqui, a importância da legislação na regulamentação dos espaços, das práticas e do comportamento dos agentes individuais e coletivos do campo da educação e saúde que, por meio de alianças, conquistaram o poder de impor, interrogar, responder e proferir um discurso autorizado e instituído sobre os agentes de enfermagem da EPEE.

Enquanto espaço institucional, a EPEE inseriu-se num campo maior de poder, constituído pela interseção de duas áreas em luta no campo da medicina, ou seja, a psiquiatria e a saúde pública, especialidades consolidadas historicamente e detentoras de projetos próprios para a formação do profissional de enfermagem ${ }^{(2)}$. A este estudo também interessa a análise do campo psiquiátrico e da enfermagem moderna. Esse espaço foi palco de atuação de diferentes agentes que, norteados por seu capital cultural, travaram um combate tácito para legitimar suas posições.

Desse modo, durante as reformas do Estado Novo, a EPEE apresentava-se como um espaço de lutas por melhores posições, de grupos que se opunham entre si, segundo determinados interesses em jogo e o seu volume de capital cultural e econômico. Esses grupos eram constituídos por médicos psiquiatras, médicos sanitaristas e enfermeiras diplomadas, que buscavam, segundo seus modos de ser e de ver, alterar as regras e regularidades inscritas na EPEE.

As fontes primárias utilizadas foram ofícios, processos e relatórios, oriundos das diversas instâncias do Ministério da Educação e Saúde Pública; a legislação de interesse do campo da educação e saúde, localizadas nos acervos: Casa de Oswaldo Cruz - Fiocruz; Arquivo Enfermeira Maria de Castro Pamphiro, da Escola de Enfermagem Alfredo Pinto - UNIRIO; CEDOC da Escola de Enfermagem Anna Nery - UFRJ; CPDOC da FGV; e as Bibliotecas do Ministério da Fazenda e do Centro de Estudos do Hospital Pinnel. As fontes secundárias foram a literatura pertinente à História do Brasil; à política de educação e saúde, com destaque para a Reforma Capanema; à História da Enfermagem Brasileira, priorizando particularmente a trajetória da EPEE e seus nexos com a EEAN.

Para subsidiar a articulação das fontes ao contexto, foi elaborado um esquema de análise diacrônica e sincrônica de fatos e eventos pertinentes ao tema. A análise da estrutura dos campos e dos respectivos sistemas de relações permitiu esclarecer as circunstâncias em que ocorreram as mudanças de rumo num determinado momento da história da EPEE.

\section{RESULTADOS}

\section{O Estado Novo, a ação sanitária e a visão psiquiátrica}

No início de 1937, o MESP, após a reformulação de sua organização central, passou a denominar-se Ministério da Educação e Saúde (MES), permanecendo no cargo o ministro Gustavo Capanema. No campo da educação, a Universidade do Rio de Janeiro e a Universidade Técnica Federal se reuniram para formar a Universidade do Brasil (UB). No campo da saúde, o então denominado Departamento Nacional de Saúde (DNS) aglutinou quatro divisões: a de saúde pública, a de assistência hospitalar, a de assistência aos psicopatas e a de amparo à maternidade e à infância. À Divisão da Assistência a Psicopatas (DAP) cabia também a profilaxia mental, em caráter nacional e local. Para a execução das atividades assistenciais no Distrito Federal, havia o Serviço de Assistência a Psicopatas do Distrito Federal (SAP), constituído pelos seguintes órgãos: o Hospital Psiquiátrico, 0 Instituto de Neuro-Síflis, o Manicômio Judiciário, e as Colônias Juliano Moreira e Gustavo Riedel ${ }^{(3)}$.

A nova organização do MES conferiu aos sanitaristas mais poder de decisão no campo da saúde. O DNS se incumbiu da administração das atividades, tanto de saúde pública como de assistência médico-social, em caráter local e nacional. Tal fato resultou da distinção e prestígio dos agentes da saúde pública e confirmou o sanitarista João de Barros Barreto como porta-voz legal no campo da saúde. Ele deveria articular e coordenar as forças em jogo no campo da saúde, mormente entre os representantes das especialidades médicas, em prol das políticas de educação e saúde.

Os sanitaristas conquistaram mais status, já que a eles tinham que se reportar os psiquiatras da DAP e SAP. No que se refere à enfermagem, a EAN e a EPEE ficaram inseridas de modo distinto na estrutura do MES: a primeira, na mais prestigiada área de ensino, e a segunda, na área de saúde desse ministério, sob o comando dos psiquiatras.

Na segunda metade do governo constitucionalista de Vargas, foram decretados sucessivos estados de sítio e de guerra, até que na noite de 10 de novembro de 1937, Vargas anunciou, pelo rádio, que o Brasil tinha uma nova Constituição. Tal ação se caracterizou como um golpe, que tinha como ideário político o corporativismo de Estado. Nesta concepção, a organização social deveria se dar através dos ramos de produção, isto é, através das corporações, ao invés de pautar-se nas instituições representativas da democracia liberal. Assim, o corporativismo prescrevia que as atividades políticas fossem substituídas por trabalhos técnicos em comissões e conselhos de grupos profissionais ou econômicos, organizados e liderados por um Estado fortalecido; no Brasil, o corporativismo consubstanciou-se no Estado Novo(4).

No que se refere à modernização, destacou-se a política de pessoal para os funcionários públicos, que estabeleceu o concurso, a estabilidade e o mérito, tendo sido, em 1938, oficializado o Departamento Administrativo do Serviço Público (DASP). Cabe destacar que, na ausência do Poder Legislativo pelo fechamento do Congresso Nacional, o DASP ampliou suas funções, na medida em que passou a cuidar do orçamento da União e dos estados, além de assessorar os interventores estaduais nomeados por Vargas. Implantava-se, assim, "a valorização do conhecimento técnicocientífico aplicado à administração, tendo como estratégia o cuidado em lidar com os interesses nacionais"(4).

Depreende-se, portanto, que a política de saúde seguia a orientação centralizadora do governo Vargas. Em 1937, foram apresentados resultados parciais de inquéritos sobre as organizações sanitárias estaduais, coordenadas pelos médicos sanitaristas Aristides Paz de Almeida e Lincoln de Freitas Filho e pelos engenheiros sanitários Mario Leal Ferreira e Vitor Leuzinger. Os resultados evidenciaram o descaso geral pela saúde das populações do interior. Nas capitais, foram verificadas deficiências no aparelhamento sanitário de combate à lepra, às doenças venéreas e à tuberculose, de amparo à maternidade e à infância, bem como de serviços de enfermagem, de laboratório, de engenharia sanitária e de educação sanitária. Por isto, os estados que desejassem receber cooperação federal deveriam contar necessariamente com uma equipe de pelo menos um sanitarista, uma enfermeira de saúde pública, um engenheiro sanitário e um técnico de laboratório(5).

As enfermeiras federais passaram a preparar visitadoras para os órgãos de saúde pública dos estados. Cabe destacar que esta atividade, antes 
atribuída diretamente às agentes enfermeiras, já correspondera, na década de 20, a uma mudança no projeto de implantação da enfermagem moderna no Brasil. Na ocasião, Ethel Parsons usara seu prestígio para extinguir a categoria de visitadora sanitária no Rio de Janeiro, a despeito da oposição dos agentes sanitaristas ${ }^{(6)}$. Esta política de treinamento de visitadoras se fez por imposição de Barros Barreto e contra a opinião daquelas enfermeiras diplomadas que ocupavam posições de liderança na categoria.

Barros Barreto também registrou os estreitos contatos do DNS com a Oficina Sanitária Pan-Americana e o cumprimento dos compromissos assumidos com pontualidade e rigor. Também foram mantidos os contratos de cooperação com a Fundação Rockefeller, que em 1937 concedeu bolsas a dois sanitaristas, Aristides Paz de Almeida e Lincoln de Freitas Filho( ${ }^{(5)}$, bem como a cinco enfermeiras: Hilda Anna Krisch, Aurora Gypsofhila de Afonso Costa, Delizeth de Oliveira Cabral, Yolanda Lindemberg, e Alayde Borges Carneiro(7) para estudar na Johns Hopkins School of Hygiene and Public Health, em Baltimore - EUA. Aqui constatamos que a FR continuava a contribuir para a inculcação e atualização do habitus profissional, tanto dos sanitaristas como das enfermeiras.

Para promover a padronização das unidades de saúde nos estados, 0 DNS elaborou projetos para Laboratórios, Centros de Saúde, Pavilhões de Isolamento e Escolas de Enfermagem. Com o respaldo do orçamento da Reforma Capanema, o DNS pôde ampliar esta iniciativa para hospitais gerais, colônias de psicopatas, sanatórios, preventórios, maternidades e centros de puericultura.

Neste momento, foi enfatizada a importância da implantação das Escolas de Enfermagem: "(...) cuja instalação em algumas das capitais brasileiras (Belém, Recife, Salvador, São Paulo e Porto Alegre), representa, em nosso país, sem receio de contestação, um dos cometimentos básicos em matéria de organização sanitária"(5).

O Serviço de Saúde Pública do Distrito Federal, sob a responsabilidade de J.P. Fontenelle, apoiava a adoção do sistema de descentralização distrital na capital do país. 0 discurso dos sanitaristas mais próximos ao diretor geral do DNS visava a conquistar recursos para a instalação de uma rede de doze Centros de Saúde, na cidade. Para os sanitaristas, a atuação das enfermeiras de saúde pública era estratégica para promover o controle das famílias em seus domicílios, para a extensão das ações dos centros de saúde, para o processo de descentralização distrital e, enfim, para o desenvolvimento da saúde pública. Por isso, no projeto sanitário constava a ampliação do serviço de visitadoras, sob o comando do Serviço de Enfermeiras do DNS.

A reforma no MES, em 1937, também daria origem às Delegacias Federais de Saúde (DFS). Seu caráter controlador sobre as organizações sanitárias estaduais se evidenciava no fato de que as inspeções técnicas das Delegacias Federais norteavam a concessão de subvenções aos serviços estaduais de saúde. As DFS completaram e atualizaram aqueles inquéritos iniciados em 1935, estendendo-os à assistência a psicopatas e aos estabelecimentos hospitalares ${ }^{(5)}$.

Seus resultados mostraram que havia no país trinta e cinco estabelecimentos públicos destinados ao tratamento e à assistência a psicopatas, predominantemente sob o sistema fechado. Os estabelecimentos eram em grande número ligados aos Departamentos Estaduais de Saúde Pública. Apenas seis contaram com serviço médico especializado; os outros desconheciam a especialização psiquiátrica. Mais grave ainda era a situação da enfermagem, pois somente seis estados foram destacados no inquérito, por assistir e tratar os seus doentes com métodos atualizados, praticando a prevenção das psicopatias e ações de serviços sociais: Estado do Rio de Janeiro, Paraná, Rio Grande do Sul, Pernambuco, São Paulo e Minas Gerais. O Distrito Federal não era citado por críticas ou elogios, tendo em vista que esta região determinava a padronização a ser seguida, no processo de centralização política e administrativa ${ }^{(5)}$.

Até àquela época, o SAP e a DAP tinham sua atenção voltada apenas para o Distrito Federal e não dispunham de especialistas em número suficiente para assumir atribuições no âmbito nacional. As mudanças decorrentes da Reforma Capanema, no âmbito da saúde, abriram espaço para as reivindicações dos agentes da psiquiatria, no espaço do DNS. 0 projeto dos psiquiatras incluía a ampliação das instalações e a elaboração de normas técnicas para as ações no campo psiquiátrico. Estes agentes queriam erradicar com urgência o modelo asilar do Hospital Psiquiátrico (ex-HNA) e implementar o modelo da higiene e profilaxia mental(5).

Sob a direção do psiquiatra Valdomiro Pires, promovido de diretor do Serviço de Assistência a Psicopatas a diretor da DAP, a Divisão traçou como meta, para o ano de 1938, concluir a passagem dos pacientes do Hospital Psiquiátrico (HP), onde a situação era dramática, para as Colônias Juliano Moreira, em Jacarepaguá, e Gustavo Riedel, no Engenho de Dentro(5). $^{(5)}$

O projeto de regulamento do SAP, elaborado pelos psiquiatras Valdomiro Pires, Heitor Carrilho e Adauto Botelho, que foi encaminhado à Comissão de Eficiência do MES, definia inclusive a proporção dos profissionais de saúde, em relação ao número de doentes, nos estabelecimentos da Assistência a Psicopatas ${ }^{(5)}$.

No contexto da reforma Capanema, os psiquiatras, diante das demandas de implantação do modelo da higiene mental, reviram as estratégias até então utilizada pela corporação de modo a estender as ações para o âmbito nacional e preparar agentes de enfermagem especialistas,.

$O$ projeto de regulamento deveria, entre outras finalidades, facilitar 0 ensino, em qualquer dos estabelecimentos da Assistência a Psicopatas, permitindo aos psiquiatras a realização de cursos de aperfeiçoamento, inclusive para médicos. Para formar agentes de enfermagem, a intenção dos psiquiatras era uma aproximação com a EAN.

Neste projeto encontramos o primeiro registro produzido pelos agentes que ocupavam as melhores posições no campo psiquiátrico sobre os nexos entre a EPEE e a EAN, conforme indica o texto aqui transcrito:

"Enquanto não se criar na Escola Ana Néri curso especializado de enfermeiros e de atendentes psiquiátricos para os dois sexos, será mantida, para aqueles fins, anexas ao Serviço de Assistência a Psicopatas, a Escola Profissional Mixta de Enfermeiros, criada pelo Decreto 791 de 27 de setembro de 1890 e que funcionará no Hospital Psiquiátrico e nas Colônias" (5).

A expressão "enquanto não se criar na Escola Anna Nery curso especializado..." indica a expectativa dos psiquiatras de que o DNS pudesse vencer as resistências da EAN, tanto em absorver a proposta de ensino para enfermeiros/as e atendentes em psiquiatria, como em incluir, no quadro de professores daquela Escola, os psiquiatras da Assistência a Psicopatas.

No entanto, a proposta de que a EAN formasse enfermeiros especialistas e atendentes em psiquiatria, de ambos os sexos, não convergia para o padrão de ensino da Escola Anna Nery, à época sob o comando da enfermeira americana Bertha Lucile Pullen. Ainiciativa não era compatível, tanto no que se referia aos candidatos do sexo masculino, como no que dizia respeito à clientela, ou seja, psicopatas. Este exemplo influenciava várias escolas de enfermagem, fundadas na vigência do padrão oficial, em relação à psiquiatria(6).

O diretor geral do DNS iniciou a tramitação dessa proposta, encaminhando-a à EAN, em 27 de maio de 1937. No entanto, como no dia 5 de julho de 1937 a EAN foi incluída na UB, como instituição complementar (Lei n 452 de 5 de julho de 1937), a Diretora da Escola, em 31 de julho, encaminhou seu parecer ao Reitor da universidade, professor Raul Leitão da Cunha, com uma opinião contrária à proposta dos psiquiatras:

"Sou de opinião que a idéia original fora exigir que a Escola Anna Nery assumisse a responsabilidade da instrução, em seu pavilhão de aulas, de algumas das cadeiras do programa dos hospitais da Assistência a Psicopatas, e absorvesse uma parte dos professores. Situação essa muito complicada e prejudicial. A Escola Anna Nery prefere não se imiscuir nesse programa, a menos que a isso fosse obrigada." Bertha Pullen, 31 de 
julho de $1937^{(7)}$.

Dezenove dias após, o Reitor da UB respondeu a Bertha Pullen, afirmando estar de acordo com a posição da Escola, no sentido de que esta não deveria participar dos programas de ensino da Assistência a Psicopatas ${ }^{(8)}$.

A negativa da diretora Bertha Pullen à solicitação do diretor geral do DNS, para que a EAN assumisse a instrução de algumas cadeiras do programa dos hospitais da Assistência aos Psicopatas, colocava em evidência as insuperáveis divergências pedagógicas entre essas duas escolas de enfermagem.

A resistência da EAN a essa proposta demonstrou que sua inserção no campo da educação Ihe conferia uma certa autonomia. Desde então, o jogo de forças no âmbito do DNS passou a se dar entre sanitaristas, psiquiatras e enfermeiras diplomadas, no sentido de impor, a partir das necessidades de cada qual, uma nova configuração para a EPEE.

As estratégias de luta e as propostas alternativas para a EPEE

No momento da reforma Capanema, a precariedade da mão-de-obra nos serviços de enfermagem era considerada um dos grandes problemas dos serviços de saúde do país. Como, a partir de 1937, a EPEE passou a ser a única escola de enfermagem inserida no DNS, os sanitaristas pensaram em utilizar esse espaço para dar conta do preparo da força de trabalho para os hospitais federais.

O DNS desejava que a EPEE preparasse um agente de enfermagem com um capital cultural menor, o que demandaria um período de tempo inferior ao utilizado na formação das enfermeiras diplomadas. A estratégia visava formar um número de agentes capaz de substituir as leigas e as religiosas nos hospitais gerais e executar atividades de enfermagem elementares, sob a supervisão da enfermeira diplomada ${ }^{(2)}$.

Os psiquiatras da DAP mantinham junto ao DNS a proposta de adequação do ensino na EPEE, de modo a preparar dois tipos de agentes de enfermagem: um com instrução primária, para ocupar as funções de assistência dos psicopatas asilados; outro, com um capital cultural intermediário, ou seja, superior ao primeiro e inferior ao dos psiquiatras, mas que os habilitasse a atuar como visitadoras, segundo o novo modelo da psiquiatria preventiva.

No início de 1937, no entanto, Barros Barreto solicitou a colaboração da Superintendente Geral de Enfermagem do DNS, enfermeira Edith de Magalhães Fraenkel, para reformular o curso e adequar a estrutura do currículo da EPEE para um curso de atendentes (denominação determinada pela reforma do serviço público federal - 1936), sendo aproveitados todos os professores psiquiatras ${ }^{(9)}$.

O parecer de Edith Fraenkel foi cauteloso. Desde logo ela deixou evidente estar cumprindo ordens superiores:

"De acordo com vossas ordens, abaixo formulo um esboço de curso para atendentes, para os hospitais da Assistência a Psicopatas, aproveitando todos os professores das escolas da supracitada Diretoria..." Edith Fraenkel, 16 de abril de $1937^{(9)}$.

Esta correspondência indica que o diretor geral e a superintendente de enfermagem ainda entendiam a EAN como um espaço do DNS, apesar da Escola já não ter sido incluída na sua estrutura na nova reorganização do MES, uma vez que esta Escola, encontrava-se em trânsito para o campo da educação, de modo a inserir-se na Universidade do Brasil, o que ocorreu três meses depois.

Com a proposta de Edith Fraenkel, as enfermeiras diplomadas passariam a ter acesso a disciplinas estratégicas e imprescindíveis ao almejado tipo de formação de enfermagem. Quanto à participação da EAN, a superintendente opinou que "poderíamos passar para o curso da Escola Anna Nery duas cadeiras: a de Organização da vida social e a de Noções de medicina social"(10).

O Diretor do DNS submeteu a sugestão de Edith Fraenkel, para o novo curso de atendentes dos estabelecimentos da DAP, à apreciação do sanitarista Décio Parreira, com a recomendação de que ele considerasse 0 aproveitamento dos vinte e um professores da EPEE. O processo foi então encaminhado ao Diretor da DAP, o psiquiatra Valdomiro Pires, cujo parecer, como seria de se esperar, foi contrário: "... Seria de desejar que existisse uma escola de enfermagem psiquiátrica, produzindo não só pessoal habilitado para os misteres da enfermagem clínica, bem como para os departamentos médico-sociais: visitadoras e guardiões, o que aliás, já se vem fazendo, em parte, na Escola 'Alfredo Pinto', do Engenho de Dentro, e que seria de todo lamentável extinguir (...) o curso de atendentes, ora em organização e que visa melhorar a lacuna apontada, mas nunca preenchê-la totalmente, deve ter as características de curso preliminar, prévio, até que se organize o curso especializado de enfermagem, cuja realização só se compreende dentro de estabelecimentos psiquiátricos..." Valdomiro Pires, 21 de junho de 1937(9).

A redução do curso da EPEE para cinco meses e a do número de disciplinas para nove, proposta por Edith Fraenkel, contrariava frontalmente o projeto dos psiquiatras, pois significaria retornar a uma formação mínima. 0 que os psiquiatras, na verdade, desejavam era elevar o nível de preparação destes agentes de enfermagem, mas de modo a garantir-thes 0 monopólio da formação dos enfermeiros/as, nos estabelecimentos da DAP.

0 argumento da DAP era o de que, além de preparar agentes para a assistência de enfermagem elementar, dever-se-ia atentar para a necessidade de especialização da enfermagem em psiquiatria. Tal especialização corresponderia a uma assistência humanizada de enfermagem, exercida na psiquiatria com uma suposta autonomia. Essa análise foi ilustrada com uma das máximas de Florence Nightingale:

"Se em outros setores da medicina, o enfermeiro tem relevante papel, na psiquiatria ele é a pedra angular. Enquanto que nas outras especialidades a sua ação é por assim dizer descontínua, como mandatário de determinações estritas, na medicina mental o enfermeiro tem ademais sua função própria, autônoma, de atuação contínua; não se encarrega só da execução de ordens recebidas; atua pelo seu carinho, confortando, distraindo o doente, desviando-os das suas tendências mórbidas, ao mesmo tempo em que the é o vigilante e o guarda... Por aí, elementarmente pode concluir o grau de especialização da enfermagem psiquiatra... Poder-se-ia, completando o que disse Florence Nightingale: 'Não pode haver comparação entre o trabalho de quem se aplica à tela morta ou ao mármore frio, com 0 de quem se consagra ao corpo vivo', dizer - e às sutilezas do espírito." Valdomiro Pires, 21 de junho de $1937^{(9)}$.

Valdomiro Pires deixa entrever, em seu parecer, a estratégia dos psiquiatras para garantir o controle sobre a enfermagem, nos estabelecimentos do SAP. Ele propunha a simples reprodução do habitus do (a) enfermeiro (a) da EPEE, que, até então, adotava uma formação realizada exclusivamente nos espaços de seu total domínio, isto é, nos hospitais e nas colônias da Assistência a Psicopatas. Já a formação de recursos humanos, que era uma das finalidades da DAP, constava no projeto do regulamento, encaminhado ao DNS, e que aguardava aprovação, sob a forma de lei( ${ }^{(5)}$.

O diretor do DAP criticou a extinção do quadro de enfermeiros da Assistência a Psicopatas, operada na reforma do serviço público. Amudança colocava em risco a denominação dos futuros profissionais formados pela EPEE, que poderiam ser rebaixados para atendentes. Ao contrário, os psiquiatras reconheciam, agora, a necessidade de haver, nos estabelecimentos da DAP, dois níveis na divisão de trabalho de enfermagem: "Atendente é guarda, praticante, vigilante, auxiliar de enfermeiro, enfim; faz parte do pessoal interno, do grau inicial da assistência médica. Destarte, as noções médicas, superiores e próprias do enfermeiro (colaborador direto e imediato do médico) e as questões de assistência social, não cabem no seu preparo [do atendente]" Valdomiro Pires, 21 de junho de $1937^{(9)}$.

A recusa dos psiquiatras em aceitar agentes de enfermagem menos preparados do que os requisitados pelas demais especialidades médicas, poderia, assim, significar um desejo de evitar o rebaixamento da 
especialidade psiquiátrica. Colocar os enfermeiros/as preparados na EPEE, em posição de inferioridade no campo de enfermagem, poderia levar ao raciocínio, por analogia, de que os psiquiatras também deveriam ocupar piores posições no campo da medicina. Tal receio tinha como principal referência os sanitaristas, que dispunham de enfermeiras diplomadas para desenvolver os programas de saúde pública.

$\mathrm{Na}$ oportunidade, aquele porta-voz sustentou que a corporação tinha competência para preparar o pessoal de enfermagem, no âmbito daAssistência a Psicopatas: "Até que esta nossa sugestão seja concretizada, e dentro do plano sugerido por essa Diretoria, isto é, a criação de um curso de atendentes, com o aproveitamento do corpo docente de ambas as escolas atualmente existentes, razoável afigura-se-nos esta organização..." Valdomiro Pires, 21 de junho de $1937^{(9)}$.

Assim foi que os psiquiatras, no mesmo momento em que buscavam substituir o do modelo asilar, pelo modelo da higiene mental, tratavam também de ampliar o currículo da EPEE, com o acréscimo de um terceiro ano, destinado a preparar visitadoras sociais. Restava, no entanto, uma questão: como tornar o enfermeiro (a) da Assistência a Psicopatas a pedra angular do modelo, se este agente não havia construído um discurso próprio sobre a enfermagem psiquiátrica.

Diante da resistência dos psiquiatras à proposta da Superintendente de Enfermagem, Barros Barreto fez retornar a questão à Edith Fraenkel, que preferiu apresentar sua opinião ao diretor do DNS de modo informal:

"Com as modificações feitas, volta tudo quase ao que estava. Não posso concordar em absoluto, com o ensino da enfermagem feita por médico. Parece-me também, que, havendo a Escola Anna Nery passado para a Universidade do Brasil, seria aconselhável ouvir a opinião da Diretora da Escola." Edith Fraenkel, 19 de julho de 1937 ${ }^{(9)}$.

Diante do impasse, Edith Fraenkel estrategicamente buscou apoio e reforço à sua posição, inserindo nessa luta a EAN, cuja diretora era a mais autorizada porta-voz sobre a formação de enfermeiras diplomadas no padrão Anna Nery. Assim, o campo da enfermagem passava a atuar com duas representantes autorizadas, uma do setor de serviço e outra da área de ensino.

Bertha Pullen logo deu um parecer que colocou em xeque a proposta da diretoria da Assistência a Psicopatas. Ela argumentou que os atendentes não tinham a instrução necessária para estudar as disciplinas oferecidas, razão pela qual os conteúdos acabariam sendo ministrados de forma muito elementar. Isto comprometeria sua compreensão sobre o mecanismo mental, exigência primordial no ambiente de doenças psiquiátricas, bem como sua percepção e interpretação dos problemas ou peculiaridades dos doentes. Sem o domínio dessa habilidade, o atendente não seria capaz de agir inteligentemente junto aos doentes mentais, por meio das técnicas e tratamentos. Ainda segundo Pullen, para atuar "confortando, distraindo e desviando as tendências mórbidas, nos casos de doenças mentais", era necessária uma boa dose de perspicácia, um alicerce rico de conhecimentos e uma riqueza de experiência e praxiterapia(9)

No que se refere ao plano de estudos, a mesma Diretora fez notar que o curso deixava de incluir uma matéria básica, a 'técnica de enfermagem', sem a qual, segundo ela, os conteúdos teóricos da medicina não teriam valor para 0 atendente, que iria assistir ao doente em sua vida íntima, no cotidiano hospitalar ${ }^{(9)}$.

Mas o ponto nevrálgico da questão era a autonomia das enfermeiras sobre o ensino da enfermagem. Bertha Pullen afirmou a necessidade da presença de enfermeiras diplomadas em todas as etapas da formação dos atendentes. Estes últimos teriam que ser fiscalizados por enfermeiras instrutoras, em sua aprendizagem prática nas enfermarias, diariamente, durante todo o estágio hospitalar. E o curso de enfermeiros/as deveria ser também desenvolvido por enfermeiras instrutoras, com experiência comprovada e detentoras da melhor formação possivel, a fim de que suas aulas de enfermagem fossem coordenadas com as dos médicos.

$\mathrm{O}$ argumento final de Bertha Pullen encerrava a discussão de forma categórica: "As conseqüências inevitáveis, de actos impesados, resultantes de conhecimentos inadequados, certamente acarretam tanto criticismo sobre a Escola de Enfermagem, de boa reputação, que tenta tal programa, que não lhe convém arriscar o prejuízo que lhe poderá advir, embora a melhor boa vontade que ella pudesse ter pelo desenvolvimento da profissão. Além disso, nada mais posso dizer" Bertha Pullen, 31 de julho de 1937(9)

Nessa ocasião, a EAN, apoiada pelo reitor da UB, Raul Leitão da Cunha, representante das elites do país, pôde redirecionar o jogo a favor das enfermeiras diplomadas. Entretanto, este impasse, iniciado na reforma Carlos Chagas, estava longe de ser superado.

Como registra Bourdieu as desigualdades existentes entre as especialidades nas escolas médicas, radica-se também nas questões de gênero, assim a participação das mulheres decresce na medida em que se sobe na hierarquia das especialidades; algumas, como a cirurgia, Ihes estão veladamente interditadas, ao passo que a pediatria, Ihe está reservada ${ }^{(11)}$.

Os psiquiatras resistiam às propostas de elevação do capital cultural na formação das alunas e dos alunos da EPEE, já que este desenvolvimento reduziria a distância e a distinção entre médicos e enfermeiras, no campo da psiquiatria, na medida em que estas agentes se tornassem capazes de elaborar um discurso próprio, denunciando as relações de dominação a que eram sujeitas.

$O$ adiamento da reorganização da EPEE, no entanto, abria espaço a interpretações concorrentes. Essa postergação dava à enfermagem a possibilidade de resistir ao efeito da imposição simbólica que adviria, fosse da parte dos psiquiatras ou dos sanitaristas.

A questão que se impunha, então, era a seguinte: para deslanchar este projeto, os sanitaristas teriam que superar obstáculos importantes. Um deles era o poder dos psiquiatras, instituído na EPEE, há quase cinco décadas. $O$ outro era o de vencer as enfermeiras diplomadas, cuja fortaleza era a EAN, sob o comando da enfermeira americana Bertha Pullen, $e$ cujas instrutoras eram brasileiras, mas que haviam reforçado seu habitus profissional nos EUA. Este grupo resistia à idéia de formar agentes de enfermagem com capital cultural inexpressivo e permitir aos agentes médicos, o controle de sua formação.

\section{Três propostas alternativas de reforma}

Diante do impasse criado em torno da reorganização da EPEE, devido às divergências entre o campo psiquiátrico, sanitário e o da enfermagem, Barros Barreto optou por instituir uma comissão, formada por porta-vozes das três áreas: o sanitarista Décio Parreiras (coordenador), o psiquiatra Valdomiro Pires e duas enfermeiras diplomadas, Edith Fraenkel e Bertha Pullen. Caberia aos legítimos representantes dos respectivos grupos estabelecer as bases e as normas de um curso de atendentes para os hospitais da Assistência a Psicopatas ${ }^{(9)}$.

Quanto à sede da Escola, houve consenso sobre as vantagens da fusão da Escola 'Alfredo Pinto' (no Engenho de Dentro) e do 'Curso Misto do Hospital Psiquiátrico' (na Praia Vermelha). Até sua implementação, os cursos se realizariam alternadamente numa e noutra escola. Sobre as instalações, foram consideradas indispensáveis uma sala para aulas teóricas e uma sala para aulas práticas, com o material de enfermagem necessário a esse tipo de ensino(9).

Quanto às disciplinas, professores e seriação, foram conservadas as normas contidas na proposta inicial da DAP, com o acréscimo da cadeira de prática de enfermagem, lecionada por enfermeira diplomada pela Escola Anna Nery, a ser cedida pela Superintendente Geral do Serviço de Enfermagem. Sobre o prazo e duração do curso, a maioria optou por um ano apenas; 0 voto divergente foi o do psiquiatra Valdomiro Pires, que opinou por dois anos. Para a admissão ao curso, seria exigido o atestado de curso primário, exame de admissão e orientação profissional (teste vocacional) ${ }^{(9)}$.

O coordenador da comissão, Décio Parreiras, sugeriu ao Diretor do DNS que o processo fosse encaminhado ao Diretor da DAP, Valdomiro 
Pires, para a redação final do regulamento do curso. Dois meses após esta tramitação, o diretor do DNS recebeu a minuta do regulamento do curso ${ }^{(11)}$.

Ao contrário do proposto pela comissão, o regulamento não incluía a disciplina técnica de enfermagem; a participação de uma enfermeira do DNS foi limitada ao ensino prático; a duração do curso seria de dois anos; a direção do Curso caberia ao Diretor do SAP, com poder para designar os professores, os quais deveriam ser médicos; era garantida a indicação, na totalidade, dos antigos professores das seções escolares da EPEE; a matrícula seria feita mediante requerimento ao Diretor da SAP, com certificado de conclusão do ensino primário; e, aos alunos que concluíssem o curso seriam oferecidos certificados de enfermeiro prático ou de atendente.

$O$ encaminhamento da minuta ao diretor do DNS foi feito nos seguintes termos: "Cumprindo vossa expressa determinação, encontrareis em anexo, o regulamento para o Curso de Atendentes do SAP, elaborado pela DAP. Foi o mesmo feito consoante às necessidades do referindo Curso, e nesse sentido ele vai a vossa apreciação para, pelas vias competentes, ser dada a devida execução." Valdomiro Pires, 13 de outubro de 1937 ${ }^{(9)}$.

Neste encaminhamento, percebemos a intenção do psiquiatra Valdomiro Pires de convencer o diretor do DNS de que o teor do regulamento atrelavase às necessidades do curso e não aos interesses dos psiquiatras. Também parece ter havido uma insinuação, no sentido de que o Diretor do DNS desse imediata execução a esta regulamentação, evitando que Barros Barreto o submetesse novamente à apreciação das enfermeiras, interessadas e partícipes neste jogo.

O regulamento proposto, pela primeira vez, desde a criação da EPEE, tornou explícito que o objetivo do curso seria o de preparar agentes para o exercício da enfermagem psiquiátrica ${ }^{(9)}$. Naquele momento, não se tinha conhecimento de enfermeira diplomada com especialização em psiquiatria na SAP, afastando-se assim, momentaneamente, a possibilidade de que uma enfermeira com esse capital viesse a concorrer com os psiquiatras pelos domínios da EPEE.

No entanto, o Diretor Geral do DNS houve por bem não encaminhar o processo ao ministro Gustavo Capanema. Ao contrário, Barros Barreto repetiu a estratégia inicial, submetendo o regulamento novamente à Superintendente Geral de Enfermagem do DNS, Edith Fraenkel. Em março de 1938, o Diretor Geral do DNS recebeu seu parecer. Nele, Edith Fraenkel além de reforçar aspectos já destacados por Bertha Pullen, procurou enfatizar a impossibilidade do curso de atendentes atingir seus objetivos, no que se referia à formação de profissionais de enfermagem. 0 ponto central da crítica era o processo pedagógico desenvolvido por psiquiatras e as condições para o aprendizado prático. A superintendente Geral argumentou ainda que interessava ao DNS que os futuros atendentes pudessem atuar em outras áreas da saúde, que não a psiquiatria.

No que se refere à duração do curso, Edith Fraenkel insistiu também que este fosse de um ano, uma vez que a experiência prática prevista limitava-se àquela oferecida pelos hospitais psiquiátricos, ou seja, doenças e acidentes ocorridos em uma população de quatro a cinco mil pessoas. Se o SAP insistisse em dois anos, os alunos deveriam ser obrigados a um estágio de um ano em um hospital geral, que lhes oferecesse experiência prática em outras especialidades (clínica, cirurgia, pediatria, otorrinolaringologia e oftalmologia).

Quanto às exigências para o ingresso no curso, Edith Fraenkel alertou que o nível de instrução primária limitaria, em quantidade e em qualidade, o ensino teórico a ser oferecido. Quanto ao ensino prático, ela destacou que o trabalho diário nas enfermarias deveria ser obrigatório para todos os alunos, pois só nas enfermarias os alunos têm oportunidade de exercitar aquilo que aprenderam em aula:

"O valor da technica, por mais simples que seja, só se aprende pelo processo de aplicação ao doente e pela observação dos resultados obtidos." Edith Fraenkel, 2 de março de $1938^{(9)}$

Ainda no mês de março, Barros Barreto elaborou uma outra proposta, a ser apresentada ao ministro Gustavo Capanema. $\mathrm{Na}$ exposição de motivos ele afirmou que: "As Escolas Profissionais de Enfermeiros nos serviços de Assistência a Psicopatas no Distrito Federal, (...), não atendem às suas finalidades. São escolas de padrão pouco elevado. Mais escolas de atendentes..."(9).

A seguir justificou a necessidade da constituição de dois tipos de agentes, a serem formados nas duas escolas de enfermagem oficiais, porém distintos quanto à sua inserção no campo da saúde:

"Atendentes são, porém, necessários em grande número e por certo também enfermeiros com prática psiquiátrica. Cumpre fazer uns e outros: os primeiros na atual escola, as enfermeiras na Escola Anna Nery, em curso de especialização.

Daí o estudo que foi feito por esta Diretoria Geral com a cooperação da DAP, da Superintendência de Enfermagem e da diretoria da Escola Anna Nery e de que resulta a sugestão que trago ao conhecimento de V. Ex. da organização de uma Escola de Atendentes no Serviço de Assistência a Psicopatas..." (9).

Barros Barreto assinalava que a proposta final, elaborada no DNS, para a reorganização da EPEE, havia sido pautada nas propostas dos psiquiatras e das enfermeiras diplomadas. Dessa forma, procuramos demonstrar, comparativamente, no Quadro 1, os principais pontos das propostas em questão.

A proposta final de estruturação da EPEE, concluída pelo sanitarista Barros Barreto, visou a atender às necessidades do campo médico, quanto à formação de duas novas modalidades de exercentes de enfermagem. Ambas teriam habitus diferenciado das enfermeiras diplomadas, de acordo com os interesses dos agentes psiquiatras e sanitaristas, que ocupavam posições hierárquicas distintas, porém superiores às das enfermeiras diplomadas no DNS.

Sabe-se que em toda troca está implícita uma relação de poder, na qual um emissor dotado de autoridade social, mais ou menos reconhecida, dirige-se a um receptor, que reconhece, mais ou menos, essa autoridade; e que uma parte considerável do que se passa na comunicação permanece ininteligível, enquanto não levarmos em conta essa estrutura de poder ${ }^{(11)}$.

Nas negociações sobre a reorganização da EPEE, psiquiatras e sanitaristas se colocaram como grupos emissores de propostas para a Escola, enquanto as enfermeiras diplomadas, na função de receptoras, tratavam de resistir a elas. No entanto, os sanitaristas, em posição privilegiada na estrutura do DNS, enquanto mediavam as propostas concorrentes, instrumentalizavam as divergências existentes entre psiquiatras e enfermeiras diplomadas, para fazer valer seus interesses e a visão do DNS sobre a EPEE.

A luta simbólica que ocorreu nos espaços de intersecção dos campos da saúde pública, da psiquiatria e da enfermagem, teve como ponto central de disputa a indicação do tipo de exercente de enfermagem a ser preparado pela EPEE. No entanto, foram excluídos dessa luta, tanto os enfermeiros e enfermeiras formados pela EPEE, que atuavam nos estabelecimentos da SAP, como os alunos da EPEE, já que nem uns nem outros dispunham de capital cultural ou de um discurso articulado, de modo a que pudessem se fazer ouvir.

$\mathrm{Na}$ falta de discurso e porta-voz, profissionais e alunos da EPEE acabavam representados pelos agentes dos campos da psiquiatria, da saúde pública e da enfermagem moderna, os quais contrariavam seus anseios na medida em que usavam estratégias de ocupação das melhores posições na própria Escola, bem como em seus respectivos campos.

Ao final da tramitação do processo sobre a formação de pessoal de enfermagem na EPEE, caberia ao ministro Capanema a decisão final sobre sua reorganização. Assim, a partir de 1938, a luta desses agentes transcende a área da saúde e ocupa também o campo da educação. As partes interessadas aguardavam, o pronunciamento $d$ o ministro sobre as posições a serem ocupadas pelos grupos de agentes envolvidos na disputa pelo espaço social da EPPE. 


\begin{tabular}{|c|c|c|}
\hline Comissão mista (11/08/1937) & Divisão de Assistência a Psicopatas (13/10/1937) & Departamento Nacional de Saúde (24/03/1938) \\
\hline \multicolumn{3}{|c|}{ Quanto à sede: } \\
\hline Fusão das seções escolares. & $\begin{array}{l}\text { Duas seções escolares, e internato na seção } \\
\text { feminina. }\end{array}$ & $\begin{array}{l}\text { Duas seções escolares. O curso ocorreria } \\
\text { alternadamente em cada seção. }\end{array}$ \\
\hline \multicolumn{3}{|c|}{ Quanto às instalações: } \\
\hline Salas de aulas teóricas e práticas equipadas. & Não citou. & Cita a falta de instalações adequadas. \\
\hline \multicolumn{3}{|c|}{ Quanto às disciplinas: } \\
\hline $\begin{array}{l}\text { Onze disciplinas lecionadas pelos psiquiatras da } \\
\text { DAP; uma disciplina (Técnica de Enfermagem) } \\
\text { lecionada por enfermeira diplomada do DNS. }\end{array}$ & $\begin{array}{l}\text { Onze disciplinas lecionadas pelos vinte e um } \\
\text { professores da DAP, à enfermeira caberia apenas o } \\
\text { acompanhamento dos alunos nas aulas práticas no } \\
\text { hospital. }\end{array}$ & Onze disciplinas lecionadas pelos psiquiatras. \\
\hline \multicolumn{3}{|c|}{ Quanto à duração: } \\
\hline Um ano. Com voto contrário do psiquiatra. & Dois anos. & Dezoito meses. \\
\hline \multicolumn{3}{|c|}{ Quanto à admissão: } \\
\hline $\begin{array}{l}\text { Curso primário; } \\
\text { Exame de admissão; e orientação profissional. }\end{array}$ & $\begin{array}{l}\text { Curso primário; } \\
\text { Exame de admissão (em igualdade de condições, } \\
\text { teria preferência o funcionário da SAP). } \\
\text { Orientação profissional (julgamento pelo diretor da } \\
\text { DAP). }\end{array}$ & $\begin{array}{l}\text { Certificado de estudos primários; } \\
\text { Exame de suficiência (aritmética, português, história e } \\
\text { geografia do Brasil); e exame de aptidão profissional. }\end{array}$ \\
\hline \multicolumn{3}{|c|}{ Quanto à direção: } \\
\hline Não citou. & Diretor do Serviço da Assistência a Psicopatas. & Não citou. \\
\hline \multicolumn{3}{|c|}{ Quanto à especialização de enfermagem psiquiátrica: } \\
\hline Não citou. & Não citou. & $\begin{array}{l}\text { Curso de seis meses e cinco disciplinas, desenvolvido } \\
\text { na EAN. }\end{array}$ \\
\hline
\end{tabular}

Fonte: Processo n 14276/38 - Departamento Nacional de Saúde / MES, 1938.

Quadro 1. Propostas da comissão mista de sanitarista, psiquiatra e enfermeiras, da DAP, e do DNS, para a reorganização do curso da EPEE, 1937-1938.

\section{CONSIDERAÇÕES FINAIS}

As estratégias de luta que psiquiatras, sanitaristas e enfermeiras diplomadas utilizaram para fazer valer seus projetos para a Escola Profissional de Enfermeiros e Enfermeiras, caracterizaram uma árdua batalha inserida em um jogo de forças maior. A análise dos dez meses de tramitação do Processo $n^{0} 14276 / 38$ - DNS/MES evidencia o conflito entre agentes psiquiatras, sanitaristas e enfermeiras diplomadas, para impor uma nova ordem à Escola.

A complexidade do problema para o Departamento Nacional de Saúde era a de que, ao mesmo tempo em que o diretor do DNS necessitava da anuência das enfermeiras diplomadas, aliadas dos sanitaristas, para fazer valer a formação do enfermeiro auxiliar, ele também não poderia interferir na posição ocupada pelos médicos, nas seções da EPEE, o que abalaria as relações entre sanitaristas e psiquiatras no campo da medicina. Tanto assim que, no processo de reorganização da EPEE, iniciado em 1937, o diretor geral do DNS, João Barros Barreto, alertava os porta-vozes dos campos da saúde pública e da enfermagem de que deveriam garantir em suas propostas, a manutenção dos postos dos professores psiquiatras, de ambas as seções escolares da EPEE.

$\mathrm{O}$ argumento com que os psiquiatras defendiam seu projeto para a EPEE era o de que o conhecimento a ser incorporado pelos enfermeiros (as) deveria pautar-se pelas especialidades médicas, em detrimento de um conhecimento mais específico de enfermagem. Deste modo, na formação do enfermeiro (a) seria inculcado o reconhecimento à supremacia do médico e a dedicação à sua pessoa.

A continuidade desta pesquisa demonstrou que, o jogo de forças na luta pela reestruturação do ensino de enfermagem continuaria no período do Estado Novo. Circunstâncias como a precária assistência de enfermagem desenvolvida nos hospitais e a conjuntura da segunda guerra mundial acabariam levando o ministro Gustavo Capanema a se aproximar da disputa pela reorganização da EPEE.

\section{REFERÊNCIAS}

1. Boudieu P. Razões práticas: sobre a teoria da ação. Campinas (SP): Papirus; 1997.

2. Amorin WM. A reconfiguração da primeira Escola de Enfermagem Brasileira: a missão de Maria de Castro Pamphiro, 1937-1949 (tese). Rio de Janeiro (RJ): Escola de Enfermagem Anna Nery, Universidade Federal do Rio de Janeiro; 2004.

3. Ministério da Educação e Saúde (BR). Lei 378, de 13 de janeiro de 1937. Dá nova organização ao Ministério da Educação e Saúde Pública. Diário Oficial da União; 1937.

4. D’Araújo MC. A Era Vargas. São Paulo (SP): Editora Moderna; 2000.

5. Ministério da Educação e Saúde Pública (BR). Relatórios dos Serviços Federais de Saúde. Departamento Nacional de Saúde. Rio de Janeiro (DF): Ministério da Educação e Saúde Pública; 1937.

6. Universidade Federal do Rio de Janeiro. Escola de Enfermagem
Anna Nery. Ofício EAN/10. Rio de Janeiro (DF): Universidade Federal do Rio de Janeiro; 1937.

7. Universidade Federal do Rio de Janeiro. Reitoria. Ofício UB/ 2940 S/1618. Rio de Janeiro (DF): Universidade Federal do Rio de Janeiro; 1937.

8. Fundação Getúlio Vargas. Centro de Pesquisa e Documentação de História Contemporânea do Brasil. Processo 14276/38 do Departamento Nacional de Saúde. Rio de Janeiro (RJ); 1938. GCg 38.03.24-A.

9. Barreira IA, Batista SS. A (re)configuração do campo da enfermagem durante o Estado Novo (1937-1945). Rev Bras Enferm 2002;55(2):205-16.

10. Miranda CL. O parentesco imaginário. São Paulo (SP): Cortez; 1994.

11. Bourdieu P. A dominação masculina. Rio Janeiro (RJ): Bertrand do Brasil; 1999. 